\title{
Crítica à educação ambiental no ensino de geografia: discussão e propostas pedagógicas
}

\author{
Guilherme Pereira Cocato \\ Universidade Estadual Paulista. \\ Presidente Prudente. São Paulo. Brasil \\ guilherme_pereira@yahoo.com.br \\ (1) 0000-0003-4462-8177
}

\section{revista}

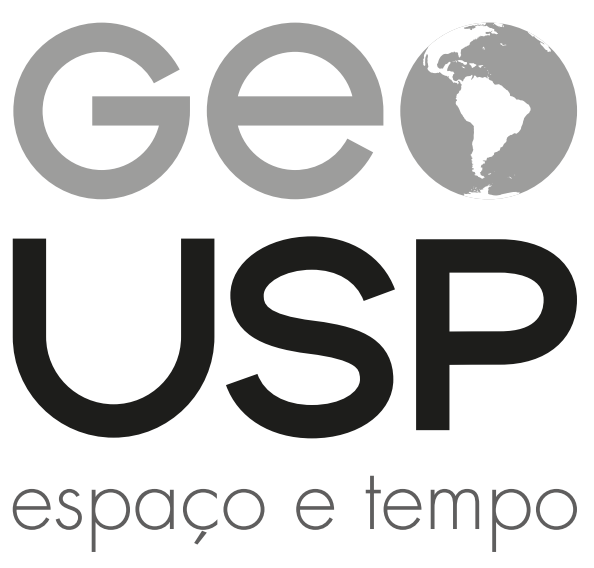

Volume $25 \bullet n^{\circ} 1(2021)$

ISSN 2179-0892 e-158138

Como citar este artigo:

COCATO, G. P. Crítica à educação ambiental no ensino de geografia: discussão e propostas pedagógicas. Geousp, v. 25 , n. 1, p. 1-21, e-158138, 2021. ISSN 2179-0892.

Disponível em: https://www.revistas.usp.br/geousp/article/ view/158138. doi: https://doi.org/10.11606/issn.2179-0892. geousp.2021.158138.

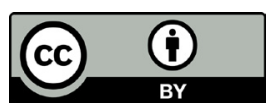

Este artigo está licenciado sob a Creative Commons Attribution 4.0 Licence 


\title{
Crítica à educação ambiental no ensino de geografia: discussão e propostas pedagógicas
}

\section{Resumo}

Este trabalho é movido por questões teórico-metodológicas acerca de práticas de educação ambiental no ensino de Geografia. O objetivo é discutir se tais atividades questionam os problemas ambientais. Procede-se a uma ampla revisão bibliográfica e se propõem atividades pedagógicas de acordo com o ensino geográfico crítico e aplicável. A crítica do materialismo histórico-dialético orienta a discussão da problemática ambiental, do ensino de Geografia, do papel dos docentes e das possibilidades alternativas de atividades didáticas. A educação ambiental é contraposta a práticas conservadoras, com alternativas didáticas passíveis de concretização. Como resultados, apresentam-se três propostas pedagógicas que permeiam conteúdos curriculares do ensino de Geografia para o ensino médio envolvendo a educação ambiental. Ressalta-se que são propostas adaptáveis a diferentes realidades educacionais e que demandam envolvimento ativo de professores e estudantes. É essencial que a discussão e as propostas se traduzam em prática efetiva a partir do enfoque nos saberes cotidianos dos estudantes.

Palavras-chave: Educação ambiental. Ensino de Geografia. Pedagogia histórico-crítica. Materialismo. Degradação ambiental.

\section{Critique of environmental education in geography teaching: discussion and pedagogical proposals}

\begin{abstract}
This work is driven by theoretical-methodological questions concerning environmental education practices in Geography teaching. The objective is to discuss whether these pedagogical activities have a questioning character of the environmental problems. A wide bibliographic review and proposal of pedagogical activities are adopted according to the critical and applicable
\end{abstract}


geographical teaching. The criticism of historical-dialectical materialism guides the discussion of the environmental problem, the teaching of Geography, the role of teachers and the alternative possibilities of didactic activities. Environmental education is discussed, opposing conservative practices with possible didactic alternatives. As results, three pedagogical proposals are presented that permeate curricular contents of Geography teaching for high school, including environmental education. They are suggested to be adaptable to different educational realities, which require the active involvement of teachers and students. It is essential that the discussions and proposals are rendered into effective practices, based on the student's everyday knowledge.

Keywords: Environmental education. Geography Teaching. Historical-critical pedagogy. Materialism. Ambiental degradation.

\section{Crítica a la educación ambiental en la enseñanza de la geografía: discusión y propuestas pedagógicas}

\section{Resumen}

Este trabajo está impulsado por preguntas teóricas y metodológicas sobre las prácticas de educación ambiental en la enseñanza de la geografía. El objetivo es debatir si estas actividades pedagógicas tienen una naturaleza cuestionable de los problemas ambientales. Adopta un examen bibliográfico y propuestas de actividades pedagógicas de acuerdo con la enseñanza geográfica crítica y aplicable. La crítica del materialismo histórico-dialéctico guía las discusiones sobre el problema ambiental, la enseñanza de la geografía, el papel de los profesores y las alternativas posibles de actividades didácticas. La educación ambiental se discute en oposición a las prácticas conservadoras. Se presentan tres propuestas pedagógicas que impregnan contenidos curriculares de la enseñanza de la geografía para la escuela secundaria, relacionándose a la educación ambiental. Son propuestas adaptables a diferentes realidades educativas, que exigen la participación activa de profesores y estudiantes. Es esencial que las discusiones y propuestas se conviertan en prácticas efectivas.

Palabras clave: Educación ambiental. Enseñanza de Geografía. Pedagogía histórico-crítica. Materialismo. Degradación ambiental. 


\section{Introdução}

Nos dilemas históricos definidos pelas crises estruturais recorrentes do capitalismo global que afeta a todos os elementos, seres e indivíduos em âmbito socioambiental - abre-se também uma oportunidade à ruptura. Os eventos de degradação ambiental são amplamente conhecidos, com dados e informações divulgadas em ritmo constante. Emerge então a necessidade urgente de modificar as bases de produção, consumo e exploração. Nesse sentido, o ensino crítico de todos os conteúdos que nos cercam é uma tarefa de transformação social, ampla e emancipadora.

Par dialético sociedade-educação não sofre mudanças isoladamente, mas se influencia mutuamente, num movimento perpétuo de modificação. A educação pode ser articulada e redefinida a partir das ações sociais de indivíduos que interagem e compartilham um determinado espaço. Esse espaço é a base material que se pretende modificar, é o ambiente necessário de reprodução social. Portanto, o par sociedade-educação está intimamente ligado ao espaço, e, mais especificamente, ao ambiente onde se desenrolam as práticas ensinadas e aprendidas durante o processo educacional. Assim, o par sociedade-educação torna-se uma tríade: sociedade-educação-ambiente, indissociável. A partir dessa constatação, emerge a importância do debate ambiental significativo, que posteriormente poderá resultar numa produção espacial mais equilibrada, proveniente das ações de indivíduos conscientes dessa questão.

Nesse contexto, Almeida (2000) afirma que muitas visões de educação ambiental podem ser (re)construídas e disseminadas, sendo algumas a favor de uma formação de "consciência" conservacionista/preservacionista, e outras abordagens mais críticas. Todas são reflexos e causas de atos políticos, principalmente quando se trabalha com a educação.

Ao almejar uma mudança de valores que leve à formação de uma outra educação ambiental, a questão ética se torna fundamental. Uma sociedade realmente preocupada com a equidade socioambiental deve ser uma sociedade que preze o bem-estar da maioria de seus indivíduos, se não for possível atingir a totalidade. Quando ações individuais e coletivas (pessoais, profissionais etc.) não almejam o bem-estar coletivo, mas sim o privado, caminham contra uma futura sociedade ambiental, e seus atos podem ser considerados anti-ambientais.

$\bigcirc$ objetivo geral deste estudo é discutir como se apresentam as atividades pedagógicas de educação ambiental no contexto atual de uma economia globalizada, principalmente na perspectiva do ensino de Geografia e como tais conteúdos são abordados em sala de aula. A partir das discussões teóricas e das necessidades aferidas por mudanças nos espaços educacionais, propõem-se exemplos de atividades pedagógicas orientadas por uma base epistemológica verdadeiramente crítica - de acordo com o método materialista histórico-dialético - assim como flexíveis e aplicáveis às diversas realidades escolares brasileiras.

Portanto, serão apresentados alguns elementos importantes para quem deseja buscar, em vez de uma educação ambiental conservadora e pouco efetiva (em seus princípios transformadores), outras práticas e teorias ambientais que estejam comprometidos com a realidade concreta não somente na escala de pequenas ações diárias, mas com o papel do ensino de Geografia na construção teórico-prática do conhecimento que se insira no cotidiano dos educandos, permitindo-os compreender a essência ideológica e as relações de poder que mantêm a degradação ambiental em proporções crescentes. 


\section{Realidade educacional e ambiental brasileira: aspectos legais e perspectivas de mudança}

Para que reais transformações ocorram no contexto socioambiental corrente, questionar é preciso. Questionar o modelo atual de dominação na natureza, em prol de uma ampla visão socioambiental, é questionar o modo de produção econômico-político, colocando uma crítica ferrenha para com essa organização de sociedade. E, ao mesmo tempo, é incluir no debate todos os indivíduos e povos excluídos historicamente, que tinham outras relações ambientais, mais saudáveis, e por isso mesmo foram tachados de atrasados, sofrendo intensa exploração e dominação.

Acima de tudo, é preciso questionar os conceitos de desenvolvimento e progresso que estão baseados na dominação e erradicação da natureza, causas primordiais dos atuais problemas ambientais tão exaustivamente relatados pela mídia, mas de modo descritivo e acrítico.

Em contraposição à ordem vigente, a educação, as diversas ciências e as variadas práticas pedagógicas podem ser fortalecidas e encorpadas. Mais do que nunca, deve-se ter esperança no ato de educar, que também é um ato político, ideológico e transformador. "Educar para quê e para quem é, portanto, uma pergunta cuja dimensão social a situa no cerne da chamada educação ambiental" (Brügger, 1999, p. 76). Principalmente se tratando da Ciência Geográfica, altamente responsável pela compreensão dos processos e formas socioespaciais - que podem seguir tanto a lógica desigual e excludente, como outras possibilidades diversas e emancipadoras.

Imprescindível para uma análise adequada das práticas atuais relativas à educação ambiental no ensino de Geografia, é compreender as políticas públicas e legislações que amplamente regulamentam, delimitam e implantam tais conteúdos, formal e informalmente, nas escalas federal, estadual e municipal. É importante considerar a tríade dialética sociedade-educação-ambiente nesta análise, pois tais documentos acompanham os interesses do grupo dominante nas relações de poder político-econômicas. Frente a isso, a educação, como reflexo dos interesses sociais dominantes, acaba por trilhar os mesmos princípios burocráticos. Apesar disso, os espaços pedagógicos podem contemplar práticas contrárias e subversivas da ordem vigente, o que a classifica como um importante espaço de luta e transformação socioespacial.

De acordo com a Constituição Brasileira de 1988, como atribuições do Poder Público estão a garantia de um "meio ambiente ecologicamente equilibrado, bem de uso comum do povo e essencial à sadia qualidade de vida" (Brasil, 1988, Art. 225), a fim de protegê-lo para as presentes e futuras gerações. Entre outras competências, também se encontra a promoção da "educação ambiental em todos os níveis de ensino e a conscientização pública para a preservação do meio ambiente" (Brasil, 1988, Art. 225, §1º, Inciso VI).

A Lei de Diretrizes e Bases da Educação Nacional, n. 9.394, de 20 de dezembro de 1996, também prevê que na formação básica do cidadão seja assegurada a compreensão do ambiente natural e social e que os currículos do ensino fundamental e médio devem abranger o conhecimento do mundo físico e natural (Brasil, 1996).

$\mathrm{Na}$ Política Nacional de Educação Ambiental, Lei n. 9.795/1999 (regulamentada pelo Decreto n. 4.281/2002), são definidos os princípios básicos da educação ambiental, entre outros: o enfoque humanista; a concepção do meio ambiente em sua totalidade; o pluralismo de ideias; a garantia de continuidade nos processos educativos; e a importância da ética e avaliação crítica. 
Quanto à aplicação desse tema nos diferentes espaços pedagógicos, fica garantida sua presença da educação infantil ao ensino superior e profissional (Art. 9०) - no ensino formal - e a sensibilização por meio de programas e projetos integrados entre instituições públicas e privadas - no ensino informal; ambas nas esferas federal, estadual e municipal (Brasil, 1999).

Para efetivar a educação ambiental no processo de ensino formal, os Parâmetros Curriculares Nacionais (Brasil, 1997) definem como um dos temas transversais (entre Ética, Saúde, Pluralidade Cultural, Trabalho e Consumo e Orientação Sexual) o estudo acerca do Meio Ambiente, que deve contemplar todas as disciplinas existentes de modo que a escola cumpra sua função social em termos de construção do conhecimento e valores básicos para a convivência em sociedade (Brasil, 1997).

A grande abrangência dos temas não significa que devam ser tratados igualmente; ao contrário, exigem adaptações para correspondam às reais necessidades de cada região e mesmo de cada escola. As questões ambientais, por exemplo, ganham especificidades diferentes nos campos de seringa no interior da Amazônia e na periferia de uma grande cidade (Brasil, 1997).

Recentemente, esse documento foi substituído pela Base Nacional Comum Curricular (BNCC) (Brasil, 2017), que passa a tratar os temas transversais como temas integradores, alterando drasticamente sua essência e sem defini-los de maneira precisa. Apesar de se manter o discurso de um estudo transversal desses temas, entre os quais se incluem a preservação do meio ambiente e a sustentabilidade, não se delimitam sua abordagem docente nem os objetivos de sua efetivação em sala de aula.

Considera-se essa mudança um retrocesso na educação formal brasileira, pois, além da falta de debate para a aprovação desse documento de importância nacional, a questão ambiental não é bem definida, o que a torna passível de apropriações variadas de cunho ideológico, extremamente conservadora em sua face crítica; e, por outro lado, liberal quanto às consequências da exploração econômica e de domínio de territórios vulneráveis para degradação socioespacial.

De acordo com os princípios do modo de produção de mercadorias, percebe-se que por não se sentir parte do meio natural, o ser humano só considera a adoção de medidas realmente ambientais quando estas se tornam vantajosas também economicamente. A própria existência de um consenso em torno dos problemas ambientais, e de como solucioná-los - geralmente adotando valores vinculados a ideia de desenvolvimento sustentável - é digna de desconfiança, pois, já que tantos Estados nacionais e instituições internacionais concordam sobre o caminho a seguir, por que ele não é posto em prática?

Muito dessa imobilidade em relação aos problemas ambientais e suas práticas educacionais advém do que Marques Filho (2016) chama de heranças antropocêntricas, herdadas da Antiguidade e reforçadas pelo paradigma moderno-positivista. Tais heranças são construções intelectuais coletivas, passadas de geração em geração, apoiadas por presunções teleológicas, biológicas e ecológicas que colocam o ser humano como finalidade do cosmos, superior a todas as outras formas de vida e sujeito incontestável de transformação/adaptação dos mais variados ambientes de acordo com sua vontade; tendo todos os outros elementos bióticos e abióticos a sua disposição.

Marques Filho (2016) ressalta que o maior aprendizado a ser construído nos espaços pedagógicos, a partir do caos socioambiental contemporâneo, é que a crescente geração de 
energia, produção e consumo, que caracterizam o paradigma técnico-cientificista administrado pelo capitalismo, não diminuem e nem mesmo compensam as adversidades que o atual modo de produção afirma ser capaz de resolver. Apenas os transformam em fenômenos mais agressivos, de maior intensidade e maior alcance espacial.

Como possibilidade de mudanças teórico-práticas perante este colossal desafio, o campo educacional nunca se tornará obsoleto, sendo este reflexo e, também condicionante, da sociedade que o cria. São, ao mesmo tempo, espaços pedagógicos de manutenção da ordem e subversão aos ideais difundidos. A emergência da chamada educação ambiental é parte essencial neste debate ideológico. Segundo Brügger (1999), como a questão ambiental sempre esteve associada, de uma forma ou de outra, a fatores econômicos, políticos e culturais, as preocupações e o próprio movimento ecológico se originaram a partir de lutas de caráter social.

Portanto, uma questão central se apresenta: como realizar a abordagem da educação ambiental, de forma devidamente embasada, filosófica e epistemologicamente - como parte integrante da interação dialética entre sociedade e educação - a partir de uma orientação verdadeiramente crítica e questionadora?

\section{A educação ambiental crítica a partir do ensino de Geografia}

A educação deve pertencer ao domínio do pensamento crítico e, sendo assim, deveria proporcionar os meios básicos para tornar os alunos capazes de distinguir o conteúdo dos diversos discursos, independentemente das formas com que se possam apresentar. Nesse sentido, o ensino de Geografia se alia perfeitamente aos objetivos deste estudo. Kaercher (2013) ressalta que, apesar de o ensino de Geografia passar por dificuldades em suas formulações críticas, estas dificuldades também são universais, e cabe aos professores de Geografia uma atualização, um permanente diálogo com seus métodos e com o objetivo da ciência, em sua essência já amplamente disposta a uma construção crítica do conhecimento. É preciso demonstrar que o paradigma crítico ainda pode ser amplamente explorado nos espaços pedagógicos, bem como se tornar efetivo em propostas pedagógicas concretas.

É preciso inserir novas abordagens no debate, ou até mesmo resgatar métodos abrangentes que elucidem as causas, consequências e possíveis soluções dos problemas enfrentados. A superação de uma visão reducionista passa também pela superação da vertente simplificadora que impera na maioria das discussões ambientais e de suas práticas pedagógicas.

Segundo Oliveira (2006), muitas visões ingênuas acerca das ações de combate aos problemas ambientais têm levado à sensibilização dos sujeitos, mas nenhuma modificação profunda em seus modos de pensar e agir na realidade que o cerca. São necessárias reflexões sobre as interações entre a Ciência Geográfica e a educação ambiental num contexto interdisciplinar. De acordo com Fuscaldo (1999), as graves consequências ambientais do desenvolvimento econômico atual demonstram essa necessidade, já que, inclusive, a degradação socioambiental é distribuída desigualmente no espaço geográfico.

Sem um debate teórico-metodológico mais aprofundado, a questão caminha para um apaziguamento das contradições socioambientais de um sistema cada vez mais insustentável. $\bigcirc$ resgate da dimensão política é também o resgate da ética ambiental. A questão ambiental não é apenas a 
história da degradação da natureza, mas também da exploração do ser humano (que é natural, assim como sua força de trabalho) pelo ser humano, visando ganhos econômicos em forma de privilégios.

Assim, formas de contestar o modelo de sociedade vigente, incentivando a superação da dicotomia sociedade-natureza e contribuindo para práticas geográficas críticas, são atividades pedagógicas que abordam claramente a apropriação tanto do trabalho humano como dos elementos naturais, ambas significando apropriação e degradação do meio ambiente. Nesse contexto, tem-se a teoria influenciando diretamente a prática cotidiana de formação humana para uma nova (e possível) visão de mundo.

De acordo com Braz (2012), vive-se um tempo histórico conservador e contrarrevolucionário, em que o ideário predominante induz ao desencanto, ao facilitismo e ao oportunismo. Que quer nos fazer crer no fim das ideologias e da necessidade de transformações. E quanto a isso, é preciso resistir, buscando formas teórico-práticas que indiquem novos rumos a serem trilhados; superando as condições concretas que tornam possível esse estado de coisas. É nesse sentido que Braz (2012, p. 490) se apoia nas palavras de Marx, para quem "[...] a necessidade de abandonar uma ilusão acerca de determinada condição é, antes de tudo, a necessidade de abandonar uma condição que necessita de ilusões".

Para que a discussão, as motivações e os questionamentos desfilados até este ponto adquiram forma e concretude na realidade dos espaços pedagógicos, torna-se necessário adotar uma metodologia que guie esse caminho em prol da almejada educação ambiental crítica - afastando ilusões e alienações de práticas pedagógicas conservadoras e insuficientes para o mundo atual e, especificamente, contribuindo para as possibilidades no ensino de Geografia.

\section{Metodologia}

Compreendidas as motivações e necessidades para a superação das práticas educacionais ambientais atuais - a partir das discussões teóricas realizadas - é imprescindível que se tenha um modelo didático para auxiliar no objetivo principal do trabalho: a construção das propostas pedagógicas orientadas pela abordagem crítica.

Tal abordagem é amplamente baseada no método materialista histórico-dialético, e, mais especificamente, na pedagogia histórico-crítica. $\bigcirc$ modelo pedagógico considerado foi proposto por Gasparin (2011), tornando-se uma metodologia possível de ser adaptada e utilizada em diversos conteúdos e para diferentes idades estudantis.

Para a elaboração das propostas didático-pedagógicas tornam-se necessárias definições acerca de quais séries escolares selecionar e quais materiais didáticos, presentes no cotidiano curricular do professor, utilizar como base aos conteúdos abordados. Devido ao grau mais elevado de abstração e raciocínio complexo exigido para as atividades que envolvem a proposta de Gasparin (2011) e o tema da educação ambiental crítica, optou-se por direcionar as propostas para os três anos do ensino médio.

Quanto ao material didático, foram escolhidas duas séries de livros aprovados pelo Plano Nacional do Livro Didático (PNLD) (Brasil, 2018) para servir como referência a docentes em escala nacional: a série \#Contato Geografia, por Rogério Martinez e Wanessa Garcia (2016), e a Geografia, espaço e identidade, de Levon Boligian e Andressa Alves (2016). Entre todos os livros 
aprovados pelo PNLD (Brasil, 2018), esses dois o foram justamente porque seus autores cursaram e obtiveram o grau de licenciados em Geografia pela Universidade Estadual de Londrina, mesma instituição do autor deste trabalho.

Dessa forma, procura-se entender como os conteúdos geográficos estão distribuídos nos livros didáticos e como podem ser organizados para a elaboração de propostas didáticas - para melhor aproveitá-las - que considerem, nas escalas possíveis, a realidade cotidiana dos estudantes, construindo sobre esse conhecimento o raciocínio socioambiental crítico embasado nestas e em outras referências possíveis.

Como elemento fundamental na elaboração das propostas pedagógicas para a educação ambiental a partir dos conteúdos curriculares de Geografia, reafirma-se o posicionamento do autor, que não acredita no desenvolvimento das discussões e práticas de educação ambiental como disciplina ou área do conhecimento com conteúdos fragmentados ou isolados dos demais. Portanto, as atividades são propostas de maneira integrada aos conteúdos curriculares e outras formas de conhecimento construídas nos espaços pedagógicos, para que as questões ambientais permeiem conceitos e discussões geográficas permanentemente, com elas se fortalecendo e tornando-se sempre presentes no dia a dia educacional de professores e estudantes.

\section{A metodologia utilizada}

A metodologia de Gasparin (2011) - para o qual o ensino pautado no método histórico-crítico deve abordar as contradições, dúvidas e conflitos inerentes ao conhecimento considera o questionamento fundamental para a aprendizagem crítica, e seu ponto de partida passa a não ser apenas a escola:

[...] mas a realidade social mais ampla. A leitura crítica dessa realidade torna possível apontar um novo pensar e agir pedagógicos. Desse enfoque, defende-se o caminhar da realidade social, como um todo, para a especificidade teórica da sala de aula e desta para a totalidade social novamente, tornando possível um rico processo dialético de trabalho pedagógico (Gasparin, 2011, p. 3).

Ainda segundo esse autor, o movimento prática-teoria-prática, dialeticamente, leva as informações já apreendidas da realidade, num primeiro momento, de forma caótica e cotidiana (síncrese); para a abstração teórico-metodológica da ciência (análise); por fim retornando à prática social, numa pluralidade de visões e inter-relações críticas acerca dos fenômenos estudados (síntese). Resumidamente, a prática social inicial de cada indivíduo (e da sociedade como um todo) é questionada, problematizada e teorizada, gerando o suporte científico necessário para transformar a compreensão de elementos antes desprezados.

Segundo Gasparin (2011), o retorno a prática após a teorização e apropriação crítica da realidade é fundamental. A superação do senso comum proveniente do conhecimento imediato do cotidiano só pode ser enriquecida se efetivado em ações concretas na realidade analisada.

Depois de passar pela teoria, isto é, pelo abstrato, o educando pode se posicionar de maneira diferente em relação à prática, pois modificou sua maneira de entendê-la. 
Em consequência, sua prática também não seria a mesma. Seu pensar e agir podem passar a ter uma perspectiva transformadora da realidade (Gasparin, 2011, p. 7).

Esse autor toma como base para sua proposta de didática histórico-crítica a teoria histórico-cultural de Vigotski e as etapas didáticas propostas por Saviani (1999) em seu livro Escola e democracia. Dessa junção resultaram as três etapas principais da proposta didática em questão: o ponto de partida na prática social inicial, a teorização e a volta ao concreto pela prática social final. A etapa de teorização tem três fases: problematização, instrumentalização e catarse.

De acordo com Gasparin (2011), o trabalho do professor como mediador no processo de ensino, dinamizando as atividades pedagógicas, torna possível a aprendizagem dos estudantes. Estes se apropriam e internalizam, ativa e subjetivamente, os conteúdos científicos em suas diversas dimensões, o que contribui para o alcance dos objetivos pedagógicos emancipatórios.

Para a efetivação desse processo didático, é fundamental que o professor confronte os antigos conhecimentos com os novos de modo a relacioná-los e diferenciá-los. Apesar das dificuldades existentes na burocracia escolar tradicional, a proposta de planejamento didático deve se iniciar e ser concretizada com base nos problemas socioambientais existentes na comunidade próxima dos educandos e na realidade social como um todo.

Seguindo Gasparin (2011), com base no conteúdo escolar vigente, acredita-se ser possível identificar as formas concretas desses conteúdos na realidade dos envolvidos nas práticas pedagógicas; integrando o científico com o cotidiano, problematizando-os, delimitando-os e trabalhando da forma mais adequada possível; sempre com os objetivos bem centrados na síntese teórico-intelectual final, e quais serão suas práticas transformadoras possíveis.

De forma didática, apresenta-se um modelo (Quadro 1) de um projeto de trabalho docente-discente na perspectiva histórico-crítica, com todas as suas fases detalhadas, fornecendo o embasamento teórico-metodológico, as orientações e a motivação necessárias à elaboração das propostas pedagógicas deste trabalho.

\section{Quadro 1 - Modelo didático na perspectiva histórico-crítica}

\begin{tabular}{|c|c|c|c|c|}
\hline $\begin{array}{c}\text { Prática (Nível de } \\
\text { Desenvolvimento } \\
\text { Atual) }\end{array}$ & \multicolumn{3}{|c|}{ Teoria (Nível de Desenvolvimento Imediato) } & \multirow{2}{*}{ 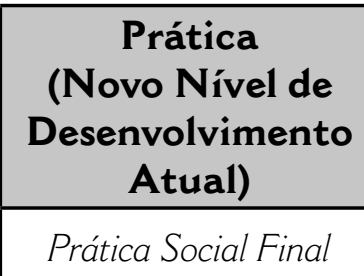 } \\
\hline Prática Social Inicial & Problematização & Instrumentalização & Catarse & \\
\hline $\begin{array}{l}1 \text { Listagem dos } \\
\text { conteúdos e } \\
\text { objetivos } \\
2 \text { Vivência cotidiana } \\
\text { do conteúdo: } \\
\text { - o que o estudante } \\
\text { já sabe } \\
\text { - desafio: o que mais } \\
\text { gostaria de saber }\end{array}$ & $\begin{array}{l}1 \text { Identificação } \\
\text { e discussão } \\
\text { dos principais } \\
\text { problemas postos } \\
\text { pela prática social } \\
\text { e pelo conteúdo } \\
2 \text { Dimensões do } \\
\text { conteúdo a serem } \\
\text { trabalhadas }\end{array}$ & $\begin{array}{l}\text { Ações docentes } \\
\text { e discentes para } \\
\text { construção do } \\
\text { conhecimento. } \\
\text { Relação estudante- } \\
\text { objeto do } \\
\text { conhecimento pela } \\
\text { mediação docente } \\
2 \text { Recursos humanos } \\
\text { e materiais }\end{array}$ & $\begin{array}{l}1 \text { Elaboração } \\
\text { teórica da } \\
\text { síntese } \\
2 \text { Expressão } \\
\text { prática da } \\
\text { síntese }\end{array}$ & \begin{tabular}{|ll}
1 & Intenções dos \\
& estudantes. \\
& Manifestação da \\
& nova postura prática \\
2 & Ações dos \\
& estudantes. Nova \\
& prática social \\
do conteúdo, \\
em função da \\
transformação social
\end{tabular} \\
\hline
\end{tabular}

fonte: Gasparin (2011, p. 159). 
Ressalta-se que a definição dos objetivos deve sempre considerar e elucidar para os educandos: o que estudar; quais os principais conceitos; a partir de que orientação político-ideológica; por que caminho teórico-metodológico; e o porquê de se aprender tal conteúdo. Assim como qual será sua aplicação significativa na prática social concreta e com que finalidades.

As etapas dessa didática não são deterministas, e o fato de formarem uma sequência lógica não significa que não conversem entre si. Elas se inter-relacionam. Assim como a prática social não está somente no início ou no final da didática, mas em toda ela e para o resto da vida do educando. Partindo da prática social próxima-remota do estudante (sincrética e naturalizada), este tem a possibilidade de (re)construir seu conhecimento ativamente.

Entende-se que esta é uma proposta didático-pedagógica complexa e desafiadora, mas que necessita da iniciativa do professor no intuito de superar as práticas tradicionais dominantes. Além de incentivar uma visão diferente, ampla e principalmente questionadora dos problemas ambientais atuais, este estudo tem como objetivo proporcionar relatos, informações, resultados (positivos e negativos) e contribuições para o debate e consequente fortalecimento das práticas críticas (e diversas) no ensino de Geografia.

Essa perspectiva de abordagem dos conteúdos socioambientais vai além em termos da responsabilidade única docente, englobando toda a sociedade e dependendo tanto da reformulação do sistema político-econômico-educacional, quanto da inerente apropriação de tais intenções e ações de transformação nas práticas cotidianas. Ambos os movimentos ocorrem de maneira integrada e dialética - proporcionando o crescimento teórico-conceitual dos indivíduos e interferindo diretamente em suas práticas sociais/cuidados ambientais - resultando em uma maior qualidade de vida individual e coletiva. Contribuindo na efetivação de tais práticas, apresentam-se em sequência as propostas pedagógicas de educação ambiental para o ensino de Geografia, elaboradas a partir da metodologia de Gasparin (2011) e guiadas pelos princípios de transformação socioambiental e crítica da produção do espaço.

\section{Resultados e discussão}

Após análise de conteúdos dos livros didáticos, foi possível selecionar grandes temas de estudo do ensino de Geografia, mais presentes no cotidiano curricular dos processos de ensino e de aprendizagem da escola básica. Entende-se que, apesar das diferenças pontuais entre abordagens teórico-didáticas, as duas séries de livros apresentam grande aproximação entre os conteúdos da Ciência Geográfica, assim como compartilham da escassa ou completa ausência do tema de educação ambiental - em quaisquer de suas vertentes em conteúdos fundamentais.

$\bigcirc$ Quadro 2 apresenta uma síntese dos conteúdos de educação ambiental nos livros didáticos aprovados no PNLD (Brasil, 2018), somando 26 capítulos ou unidades de ensino analisadas.

Quando abordadas, em aproximadamente 23\% dos conteúdos analisados, as questões socioambientais revelaram uma orientação superficial acerca de suas origens e desdobramentos atuais, apontando certas consequências (em perspectivas limitadas) e nunca expondo as causas mais profundas; não adentrando a discussão em aspectos mais sensíveis no tocante ao modo de produção capitalista ou às relações socioprodutivas que o acompanham. 


\section{Quadro 2 - Conteúdos de educação ambiental em livros didáticos de geografia para o ensino médio}

\begin{tabular}{|l|c|c|}
\hline & capítulos ou unidades & percentual (\%) \\
\hline $\begin{array}{l}\text { Abordam questões ambientais de forma abrangente, } \\
\text { aprofundada ou no mínimo satisfatória }\end{array}$ & 6 & 23,1 \\
\hline $\begin{array}{l}\text { Apresentam informações insuficientes e/ou } \\
\text { abordagem conservadora, meramente descritiva de } \\
\text { temas pertinentes à educação ambiental }\end{array}$ & 11 & 42,3 \\
\hline $\begin{array}{l}\text { Não apresentam nenhuma informação nem citam } \\
\text { temas relativos à degradação socioambiental ou } \\
\text { aos conteúdos mais recorrentes na educação } \\
\text { ambiental contemporânea }\end{array}$ & 9 & 34,6 \\
\hline total & 26 & 100 \\
\hline
\end{tabular}

fonte: Elaborado pelo autor.

Considerando a discussão até aqui realizada, entende-se que as atuais propostas teórico-práticas de atividades para a educação ambiental no ensino de Geografia não consideram o contexto contemporâneo (e nem de construção histórica) da produção capitalista do espaço, esvaziando, portanto, tais atividades de qualquer viés crítico verdadeiramente transformador e servindo como apêndices de uma educação tradicional e conservadora das desigualdades e degradações socioambientais. Portanto, torna-se imprescindível o envolvimento de docentes e pesquisadores nesse tema, em debates acadêmicos, teóricos e propostas práticas para o ensino geográfico-ambiental, se a motivação for transformar esta realidade.

\section{As propostas}

Para a elaboração de propostas significativas no âmbito da educação ambiental para o ensino de Geografia, considera-se essencial envolver a pluralidade de conteúdos apresentados no material didático, em suas formas cotidiana e científica. Desse modo, há diversas possibilidades para a transição entre a realidade dos estudantes, a construção intelectual abstrata e o retorno à concretude.

Em sequência estão descritas as propostas pedagógicas formuladas a partir da discussão realizada neste trabalho, nos conteúdos apresentados pelos livros didáticos e no desejo de abordar os conteúdos de maneira crítica e engajada com a realidade concreta. Seguindo o modelo metodológico-didático de Gasparin (2011), optou-se pelo número de três propostas, sendo uma para cada ano do Ensino Médio. Esse número de atividades foi escolhido por abarcar todos os anos curriculares para os quais as propostas didáticas foram consideradas aplicáveis, tendo em conta diversos conteúdos geográficos presentes nos livros didáticos analisados e integrando a discussão ambiental com diferentes conceitos/temas constantemente abordados nos espaços pedagógicos e aulas de Geografia. 


\section{$1^{\text {a }}$ proposta}

Disciplina: Geografia

Conteúdo: Climatologia

Temas: Clima, tempo e mudanças climáticas

Série: 10 ano do Ensino Médio

Horas-aula: 16

Objetivo geral: Compreender as dinâmicas do clima e tempo, e as causas e consequências de uma mudança climática por atividades antrópicas.

Objetivos específicos: Identificar as diferenças entre clima e tempo; discutir suas formas dinâmicas de funcionamento cíclico e eventos mais significativos; compreender a importância geográfica do clima para a espécie humana; detalhar as formas como o ser humano interfere nas dinâmicas climáticas e a origem dessas interferências; debater a existência ou não do aquecimento global, e se tal mudança tem origem antrópica; traçar as consequências atuais e tendências futuras com o agravamento dessa situação; estimar possíveis soluções para a questão e relacioná-las com os modos de produção e consumo vigentes.

Tópicos do conteúdo: Definições de clima e tempo; dinâmicas sazonais de funcionamento (estações, monções etc.); importância para atividades humanas; interferência antrópica; aquecimento global; consequências de mudanças climáticas; alternativas de desaceleração das mudanças e possíveis mitigações.

\section{Prática Social Inicial do Conteúdo:}

1 - Listagem do conteúdo e objetivos

2 - Vivência: Qual o clima da região? E o tempo? E do país? Ocorrem eventos extremos? E em outros locais do planeta? Percebem alguma alteração climática? Existe poluição do ar? Existem diferenças entre o ambiente rural e as cidades?

Desafio: $\bigcirc$ que é aquecimento global? Se existe, é causado pelo que?

Problematização:

1 - Principais questões: Quais as diferenças entre clima e tempo? Quais suas principais dinâmicas e eventos? Para o Brasil? Qual a importância do clima/tempo para o ser humano e a constituição de seu espaço geográfico? Quais técnicas mais se utilizam? Formas de previsão? Existe interferência e poluição climática por atividades humanas? Qual a relação destas com os modos de produção e consumo capitalista? Qual o nível de degradação dos sistemas atmosféricos atualmente? E as perspectivas para o futuro? Quais as diferenças entre campo e cidade? Para que servem os acordos climáticos? São funcionais e respeitados? Quais as maneiras de conter essa situação?

2 - Dimensões do conteúdo: científico/conceitual; socioambiental; histórica; econômica, política, estética, religiosa e ideológica. 
Instrumentalização:

1 - Ações docentes e discentes: Aula expositiva dialogada; leitura de texto; debate; pesquisa; exercícios e uso de mapas; observação do tempo e demonstração de formas de previsão climática e medição pluviométrica; júri simulado acerca da existência ou não do aquecimento global antrópico.

2 - Recursos humanos e materiais: docente; discentes; livros; apostilas; mapas; notícias da mídia local, nacional e internacional; registros climáticos históricos; imagens e vídeos; e instrumentos de previsão climática.

Catarse:

1 - Elaboração teórica da síntese: Compreensão dos diversos elementos e dinâmicas do clima/tempo; grande importância destes para a sobrevivência e desenvolvimento humano; identificação das principais formas de modificação e poluição climática, assim como sua relação com o advento da industrialização e o modo de produção/consumo capitalistas; impacto das indústrias e do comércio global; especificidades do campo e das cidades, ilhas de calor, inversão térmica, chuva ácida, importância da cobertura vegetal etc.; Ação dos gases de efeito estufa e aquecimento global, quais as possíveis causas e consequências; Sinais deste aumento pelo mundo e compreensão de cenários futuros; entendimento da efetividade dos acordos climáticos unilaterais; especulação acerca de quais atividades devem ser modificadas.

2 - Expressão prática da síntese: Júri simulado com argumentação em três frentes não existência do aquecimento global; aquecimento global "natural" e aquecimento por causas antrópicas.

Prática Social Final do Conteúdo:

1 - Intenções dos estudantes: Conhecer melhor o conteúdo; repensar atitudes diárias de poluição atmosférica; relação entre diferentes formas de poluição climática - comercial/industrial; reconhecer a importância do clima/tempo; buscar melhor compreensão acerca do debate sobre o aquecimento global e as intenções corporativas em posicionamentos contrários; aprofundamento na relação conflituosa entre economia capitalista e proteção/acordos climáticos; busca de transformação das perspectivas futuras.

2 - Ações dos estudantes: Ler mais sobre o assunto; pesquisar mais notícias; conversar com outras pessoas fora do ambiente escolar; pesquisar legislações; atentar-se para as ações cotidianas, de familiares e pessoas próximas; analisar as condições ambientais climáticas de acordo com as atividades socioprodutivas desenvolvidas na cidade e em áreas próximas. 


\section{2a proposta}

Disciplina: Geografia

Conteúdo: Geografia Urbana

Temas: As cidades, o urbano e suas questões socioambientais

Série: $2^{\circ}$ ano do Ensino Médio

Horas-aula: 20

Objetivo geral: Entender o processo de urbanização mundial e brasileiro relacionando-o com a produção socioambiental desigual do espaço.

Objetivos específicos: Compreender a evolução das cidades no mundo e no Brasil, de acordo com as atividades socioprodutivas da humanidade; caracterizar o fenômeno da urbanização; diferenciar a urbanização entre países colonizadores e colonizados, ao ritmo das revoluções industriais e/ou de forma acelerada; detalhar o uso diversificado e as atividades socioprodutivas que compõem o ambiente urbano; discutir as questões e desigualdades socioambientais que influenciam a qualidade de vida nas aglomerações urbanas e causam problemas ambientais.

Tópicos do conteúdo: As primeiras cidades e sua evolução espacial e histórica; os diferentes tipos de cidade; o fenômeno da urbanização; as primeiras cidades no Brasil e as ocupações concomitantes aos ciclos econômicos coloniais; a urbanização acelerada e desigual; o uso diversificado do espaço urbano; as desigualdades socioambientais e condições de vida - precarização de moradias e serviços básicos, infraestrutura e acessibilidade, exclusão socioespacial, gentrificação, vazios urbanos e especulação imobiliária, verticalização, direito à cidade, geração de resíduos, poluição, áreas verdes, erosão, assoreamento, impermeabilização do solo, ilhas de calor etc.

\section{Prática Social Inicial do Conteúdo:}

1 - Listagem do conteúdo e objetivos

2 - Vivência: Como nasceram as cidades? Quais as diferenças entre cidade e urbano? Onde vivem mais pessoas, na cidade ou campo? $\bigcirc$ que as pessoas fazem nas cidades? Qual a qualidade de vida? Em nossa cidade, existe desigualdade? Como? Por quê? Os elementos naturais são respeitados nas cidades?

Desafio: Por que existem espaços vazios na cidade? Para onde vai a poluição das cidades? Existem outras formas de constituir uma aglomeração urbana?

\section{Problematização:}

1 - Principais questões: Como surgiram e se constituíram as cidades no Brasil e no mundo? Como as atividades socioprodutivas estão ligadas às possibilidades de aglomeração coletiva? Quais os tipos de cidade existentes? O que é o urbano e como está conectado com o modo de vida capitalista-burguês pós-Revolução Industrial? Como ocorreu a urbanização nos países colonizados? E no Brasil? Quais são os principais usos do solo urbano e as atividades que constituem este ambiente? Qual a qualidade de vida pra aglomerações urbanas de grande proporção? Existem desigualdades socioambientais nas cidades? Quais são elas? 
Todos têm as mesmas condições de vida? Como podem ser transformadas? Como o modo de produção capitalista e de consumo interfere no espaço urbano, dele se utilizando e produzindo como mercadoria em busca do lucro?

2 - Dimensões do conteúdo: científico/conceitual; socioambiental; histórica; econômica, política, estética, religiosa e ideológica.

Instrumentalização:

1 - Ações docentes e discentes: Aula expositiva dialogada; leitura de texto; debate; pesquisa; exercícios e uso de mapas; trabalho de campo no bairro/entorno do colégio (com duração de um turno letivo).

2 - Recursos humanos e materiais: docente; discentes; livros; apostilas; notícias da mídia local, nacional e internacional; imagens e vídeos; mapas; cadernetas, celulares (fotografias) e vestuário adequado para trabalho de campo.

\section{Catarse:}

1 - Elaboração teórica da síntese: entendimento das dinâmicas de formação e evolução diferenciadas das cidades no mundo e no Brasil; relação entre as atividades socioprodutivas e a constituição das cidades; tipos de cidades; compreensão do surgimento do urbano como modo de vida capitalista e industrial; diferenciação entre urbanizações de países colonizadores e colonizados, aceleração e desigualdades herdadas (caso brasileiro); detalhamento das atividades urbanas e uso/ocupação do solo; diferenciação das qualidades de vida possíveis nas cidades de acordo a lógica econômica do capital/lucro; compreensão das desigualdades e da degradação socioambientais como pertencentes a essa lógica de acumulação; produção do espaço geográfico capitalista urbano à imagem do modo de produção vigente, vinculado à precarização dos serviços essenciais, desigualdade de acesso e consumo, exclusão de amplas parcelas da população, outras formas de vida e condições ambientais desejáveis; desconsideração da poluição e de impactos ambientais.

2 - Expressão prática da síntese: cadernetas de campo (visualização dos conteúdos no trajeto proposto) e concurso de fotografias.

\section{Prática Social Final do Conteúdo:}

1 - Intenções dos estudantes: Conhecer melhor o conteúdo; compreender a relação entre modo de produção capitalista e constituição atual das cidades como mercadorias; pensar alternativas à degradação ambiental urbana.

2 - Ações dos estudantes: Ler mais sobre o assunto; pesquisar mais notícias; conversar com outras pessoas fora do ambiente escolar; pesquisar legislações e participar ativamente da construção do plano diretor e outros instrumentos de 
ação fundamentais; atentar-se para as ações cotidianas, de familiares e pessoas próximas; analisar criticamente as possibilidades de transformação socioambiental em cidades imersas na lógica da acumulação e do lucro; buscar formas de emancipação teórico-práticas contínuas.

\section{3a proposta}

Disciplina: Geografia

Conteúdos: Natureza, sociedade e problemas socioambientais

Temas: A degradação socioambiental global por meio da produção capitalista do espaço

Série: 30 ano do Ensino Médio

Horas-aula: 20

Objetivo geral: Detalhar as diversas formas de degradação ambiental em curso no planeta, qual sua relação com a produção capitalista do espaço e como ameaçam a sobrevivência de todas as formas de vida.

Objetivos específicos: Conceituar degradação ambiental e sua relação intrínseca com o social; relacionar o capitalismo e a produção de seu espaço com as crises socioambientais e as contradições de seu desenvolvimento; detalhar e debater, em diversas escalas, as formas de degradação ambiental existentes e o peso de seu agravamento nas perspectivas das gerações humanas atual e futuras, assim como para outras formas de vida e as complexas dinâmicas ambientais do planeta como sistema.

Tópicos do conteúdo: $\bigcirc$ que é degradação ambiental e como está intimamente ligada ao aspecto social; a ocorrência da produção capitalista do espaço fundada na exploração, degradação e extinção das formas de vida; a contradição da forma de desenvolvimento atual e do colapso socioambiental e de recursos dos quais depende; as diversas formas de degradação ambiental e seu contínuo agravamento - desmatamento; água; solos; insegurança alimentar; resíduos, efluentes e contaminação industrial; exploração e poluição por combustíveis fósseis; mudanças climáticas; problemas demográficos; colapso da biodiversidade; grandes obras (hidrelétricas e usinas de energia); urbanização etc.

\section{Prática Social Inicial do Conteúdo:}

1 - Listagem do conteúdo e objetivos

2 - Vivência: $O$ que é degradação ambiental? E social? Estão conectadas? Percebe-se esses tipos de degradação no dia a dia? Quais os problemas que enfrentamos nas cidades (lixo, alagamentos, poluição do ar, aumento de temperaturas entre outros)? A situação ambiental sempre foi assim? Está melhorando ou piorando? Por quê? Quais as notícias que mais vemos relacionadas aos problemas ambientais? Como mudar esse cenário?

Desafio: Os problemas ambientais são acidentais ou podem ser evitados? Como? Com tecnologia, conseguiremos resolvê-los? Por que ainda não melhoramos as condições ambientais da nossa cidade, estado, região, país, continente e/ou planeta? 


\section{Problematização:}

1 - Principais questões: $\bigcirc$ que é degradação ambiental e social? Como ocorrem? Qual a conexão entre o modo de produção capitalista do espaço e de suas relações sociais e a existência de problemas ambientais? Por que os elementos naturais são tratados de forma agressiva, como recursos, sendo que deles dependemos e podem se esgotar? Quais os tipos de degradação/problemas ambientais existentes? Variam de acordo com as regiões do planeta? Estão relacionados a que atividades humanas? Interferem na vida de outros seres vivos e na dinâmica do planeta? Como mudar essa situação?

2 - Dimensões do conteúdo: científico/conceitual; socioambiental; histórica; econômica, política, religiosa, estética e ideológica.

\section{Instrumentalização:}

1 - Ações docentes e discentes: Aula expositiva dialogada; leitura de texto; debate; pesquisa; exercícios e uso de mapas; exposição de mapas temáticos elaborados de acordo com o rigor cartográfico, para mostra dos problemas socioambientais dos bairros onde vivem os estudantes.

2 - Recursos humanos e materiais: docente; discentes; livros; apostilas; notícias da mídia local, nacional e internacional; imagens e vídeos; mapas e materiais artísticos para confecção dos mapas temáticos.

\section{Catarse:}

1 - Elaboração teórica da síntese: Compreensão da essência da degradação e dos impactos ambientais e sociais e como estão relacionados; aprofundamento acerca das causas desses impactos e como estão ligados às relações socioprodutivas do capitalismo, que se manifestam na produção do espaço à sua imagem; entendimento das contradições de tratamento dos elementos naturais pelas relações capitalistas, que deles dependem, mas ao mesmo tempo os esgotam; detalhamento dos tipos de degradação/problemas ambientais existentes por dados confiáveis (históricos e recentes) e suas amplas extensões pelo planeta (ultrapassando limites de países e, portanto, sendo problemas de todos); correlação das atividades socioprodutivas como agropecuária, produção industrial, extração mineral e de outros recursos naturais, construção de grandes obras de transportes e geração de energia, extração e consumo de combustíveis fósseis, aglomerações urbanas etc. com as degradações ambientais deles decorrentes; estudo do impacto em todas as formas de vida existentes e nas complexas dinâmicas do planeta, que se inter-relacionam e interdependem; formulação de opiniões e posicionamentos acerca de possíveis mudanças que levem à transformação desse cenário. 
2 - Expressão prática da síntese: Mapas temáticos acerca dos problemas ambientais nos bairros de vivência dos estudantes.

\section{Prática Social Final do Conteúdo:}

1 - Intenções dos estudantes: Conhecer melhor o conteúdo; compreender a relação entre modo de produção/consumo capitalista e suas expressões concretas na produção do espaço desigual e degradado; aprofundar-se nas contradições que causam tais impactos ambientais e a extensão de sua gravidade, desde a escala cotidiana à escala global.

2 - Ações dos estudantes: Ler mais sobre o assunto; pesquisar mais notícias; pesquisar legislações pertinentes; pesquisar fontes de dados confiáveis acerca dos problemas ambientais contemporâneos; conversar com outras pessoas fora do ambiente escolar; analisar o comportamento de figuras importantes neste debate; analisar criticamente as notícias, o papel da mídia e das instituições capitalistas, nas diversas escalas de produção do espaço e degradação ambiental, associando as atividades socioprodutivas com os impactos ambientais; buscar formas de atuação, nas escalas possíveis, a partir de legislações, acadêmica e/ou profissionalmente para transformar as previsões de cenários piores e talvez irreversíveis.

Ressalta-se que, de acordo com as orientações metodológicas de Gasparin (2011), adota-se neste estudo a flexibilidade necessária para a execução das atividades dentro das propostas pedagógicas, em cada realidade escolar específica. De nenhuma maneira, este estudo pretende esgotar as possibilidades de abordagem crítica destes conteúdos ou tornar-se enrijecido a partir de uma determinada metodologia e método científico-epistemológico; mas sim apresentar novas ideias e possibilidades (executáveis ou não, de acordo com cada cenário pedagógico) para o ensino geográfico cotidiano comprometido com a transformação socioambiental.

\section{Considerações finais}

Ao longo do trabalho, o raciocínio foi guiado pelo método materialista dialético e crítico, com abordagens teóricas amplas dos principais temas do objeto de estudo. Nesse contexto, destaca-se a importância do método crítico como motivador e orientador de transformações socioespaciais, abstratas e concretas, da Ciência Geográfica como campo de ensino, pesquisa e atuação em temas ambientais e, finalmente, do papel do docente, que, por meio de postura engajada e combativa, pode modificar as atividades pedagógicas, tornando-as mais significativas ao aproximá-las dos discentes e relacioná-las com suas experiências.

Para isso, a educação ambiental abordada nas aulas de Geografia é essencial, assim como a busca de transformação teórico-prática nesse tema se associa diretamente à mudança de paradigma do ensino tradicional ainda vigente. No contexto do problema geral do trabalho, inferiu-se que as abordagens predominantes nas atividades de educação ambiental atuais reforçam as relações sociais do modo de produção capitalista, caracterizando-se como conservadoras do estado contemporâneo de degradação socioambiental. Ao culpabilizar as práticas individuais, 
o debate ambiental educativo torna-se superficial e irrelevante, situação comprovada pela análise de conteúdos em livros curriculares de Geografia.

Nesse sentido, as propostas pedagógicas elaboradas podem ser consideradas modelos solidamente embasados para construções pedagógicas mais abrangentes e também adaptáveis a diferentes realidades escolares do ensino ambiental e geográfico. São formas de materializar, a partir dos espaços pedagógicos, anseios transformadores e compreensivos do contexto socioambiental promovido pelo modelo capitalista, aprofundando a construção crítica do conhecimento e o raciocínio dos envolvidos.

A organização, criatividade e elaboração das práticas pedagógicas preferivelmente devem atender e se adequar à realidade escolar em termos subjetivos e objetivos, ou seja, devem contemplar as necessidades não apenas do conteúdo proposto a partir do método crítico, mas também da realidade local dos estudantes, suas experiências e possibilidades materiais dentro e fora do ambiente escolar. Para isso, espera-se que o docente se sinta inspirado por tais propostas, modificando-as e adaptando-as à duração, à sequência e a conteúdos a ser construídos e atividades propostas.

Reitera-se a intenção de que, em busca de um ensino geográfico plural e questionador, os processos de produção do espaço capitalista precisam de um olhar mais detalhado, imerso nas relações socioprodutivas e espaciais, a fim de compreender como acontecem a degradação e a exclusão socioambiental e como esse conhecimento pode ser construído em conjunto com os estudantes. Ultrapassa-se, assim, a educação ambiental como conteúdo isolado, integrando-a ao ensino de Geografia e diversas disciplinas, num movimento contínuo que pode concorrer para o entendimento não só dos conteúdos curriculares, mas de conhecimentos e formas de raciocínio relevantes para a vida em sociedade e a emancipação do indivíduo como sujeito crítico e transformador.

\section{Referências}

ALMEIDA, M. I. S. A emergência da educação ambiental no cenário mundial: evolução dos conceitos e concepções da educação ambiental. Boletim Goiano de Geografia, Goiânia: UFG, v. 20, n. 1-2, p. 19-41, jan./dez. 2000. Disponível em: https://www.revistas.ufg.br/ bgg/article/view/4227/3695. Acesso em: 20 abr. 2018.

BOLIGIAN, L.; ALVES, A. Geografia, espaço e identidade: ensino médio. São Paulo: Editora do Brasil, 2016. 3v.

BRASIL. Ministério da Educação. Secretaria de Educação Básica. Portaria n. 62. Plano Nacional do Livro Didático - PNLD 2018. Diário Oficial da União, Brasilia, 2 ago. 2017, p. 16-17. Seção 1. Disponível em: http://portal.mec.gov.br/index.php?option= com_docmanEview=download $\varepsilon$ alias $=70021$-edital-pnld-2018-resultado-finalpdfEcategory_slug=agosto-2017-pdfE-Itemid=30192. Acesso em: 20 set. 2018.

BRASIL. Ministério da Educação. Conselho Nacional de Educação. Resolução CNE/CP n. 2, de 22 de dezembro de 2017. Institui e orienta a implantação da Base Nacional Comum 
Curricular, a ser respeitada obrigatoriamente ao longo das etapas e respectivas modalidades no âmbito da Educação Básica. Diário Oficial da União, Brasília, 22 dez. 2017, p. 41-44. Seção 1. Disponível em: http://basenacionalcomum.mec.gov.br/wp-content/ uploads/2018/04/RESOLUCAOCNE_CP222DEDEZEMBRODE2017.pdf. Acesso em: 30 abr. 2018.

BRASIL. Lei n. 9.795, de 27 de abril de 1999. Dispõe sobre a educação ambiental, institui a Política Nacional de Educação Ambiental e dá outras providências. Diário Oficial da União, Brasilia, 27 abr. 1999. Disponível em: http://www.planalto.gov.br/ccivil_03/ LEIS/L9795.htm. Acesso em: 15 mar. 2018.

BRASIL. Ministério da Educação. Secretaria de Educação Fundamental. Parâmetros

Curriculares Nacionais: introdução aos parâmetros curriculares nacionais. Brasilia: MEC/SEF, 1997. Disponível em: http://portal.mec.gov.br/seb/arquivos/pdf/livro01.pdf. Acesso em: 19 mar. 2018.

BRASIL. Lei n. 9.394, de 20 de dezembro de 1996. Estabelece as diretrizes e bases da educação nacional. Diário Oficial da União, Brasilia, 23 dez. 1996. Disponível em: http:// www.planalto.gov.br/ccivil_03/leis/L9394.htm. Acesso em: 23 mar. 2018.

BRASIL. Casa Civil. Constituição da República Federativa do Brasil. Brasilia, DF, 1988.

Disponível em: http://www.planalto.gov.br/ccivil_03/constituicao/constituicao.htm. Acesso em: 19 mar. 2018.

BRAZ, M. Capitalismo, crise e lutas de classes contemporâneas: questões e polêmicas.

Serviço Social \& Sociedade, São Paulo, n. 111, p. 468-492, jul./set. 2012. doi: http://dx.doi.org/10.1590/S0101-66282012000300005.

BRÜGGER, P. Educação ou adestramento ambiental? 2a ed. Florianópolis: Letras Contemporâneas, 1999.

FUSCALDO, W. C. A geografia e a educação ambiental. Revista Geografia, Londrina, v. 8, n. 2, p. 105-111, jul./dez. 1999. doi: http://dx.doi.org/10.5433/2447-1747.1999v8n2p105.

GASPARIN, J. L. Uma didática para a pedagogia histórico-crítica. $5 \mathrm{a}$ ed. Campinas, SP: Autores Associados, 2011.

KAERCHER, N. A. O gato comeu a geografia crítica? Alguns obstáculos a superar no ensino-aprendizagem de Geografia. In: PONTUSCHKA, N. N.; OLIVEIRA, A. U. (Org.).

Geografia em perspectiva: ensino e pesquisa. 4a ed. São Paulo: Contexto, 2013. p. 221-231.

MARQUES FILHO, L. C. Capitalismo e colapso ambiental. 2a ed. Campinas, SP: Ed. Unicamp, 2016.

MARTINEZ, R.; GARCIA, W. Contato geografia: ensino médio. São Paulo: Quinteto, 2016.3v. 
OLIVEIRA, S. F. Educação ambiental: aspectos históricos e perspectivas. Boletim Goiano de Geografia, Goiânia: UFG, v. 26, n. 2, p. 151-166, jul./dez. 2006. doi: https:// doi.org/10.5216/bgg.v26i2.4146.

SAVIANI, D. Escola e democracia. 32a ed. Campinas, SP: Autores Associados, 1999.

Recebido em: 8 jul. 2020

Aprovado em: 5 ago. 2020 